\title{
Constitutional Morality Stimulating the Social and Health Order Issues in India
}

\author{
Virendra Singh \\ Assistant Professor, Sociology and Criminology \\ Institute of Law, Nirma University, Ahmedabad, India \\ E-Mail: virendra.sociology@gmail.com
}

\begin{abstract}
India attained the transitional phase of globalization around two decade back when the then (1991) existing government of India adapted the globalization policy. This could be considered as the impact of industrialization. But recently the nation has felt a paradigm change, when the judicial judgements shaked the minds of social scientists. Understanding of term "gender" was taken completely different from the social meaning it had. Always, it was considered that morals, values, folkways and mores were the source of law. But after discussed judgement on Navtej Singh Johar \& Ors. ...Petitioner(S) Versus Union Of India Thr. Secretary Ministry of Law And Justice(Section 377)\& Shabrimala Case it is paradigm shift in the understanding as now it could be veracious to say that law has occupied the custody to replace the traditional social control devices or diplomacies.

Keywords: Gender, Social Change, Sociology of Prediction, LGBTQ Community, Identity
\end{abstract}

\section{INTRODUCTION}

Both man and woman are enterprise of nature. They born equivalent and entre in society in akin mode. Still the ears feel a hunger to hear words like inequality, atrocities etc. as an associative of gender. In contemporary society, gender as a term looks partial and statement sounds irrational without relative terms of exploitation. This is among the major social concern and delinquency which need immediate elucidation. Anticipation with law contract gets compromised in the procedure of law attainment and statutes amendments. When India is struggling with high dependency ratio, a new perspective entered the market LGBTQ. It took long and was a hard time for the community when this fight started under the umbrella of identity crises. Earlier also people wanted to stand for their identity rights but that was a period when there was not much awareness about the other groups which could stood in support. But eventually multi- tier encounter with different foreign cultures this issue took a significate turn. Social workers and other reference groups also raised their voices in support. Slowly and gradually the movement challenged the cultural lag (Ogburn proposed concept of cultural lag, material cultural change with faster rate in comparison to non-material culture).

But on $6^{\text {th }}$ September 2018, the judgement on section 377 shaken the perspective with a message to society that nonmaterial culture too has to accept and adjust with the accelerated speed of juggernaut of social change. As this judgement could be questioned by present society but this is the stone set for building future generations.

\section{REVIEW OF LITERATURE}

Health Institution is ignored in whole discussion which should have remained the main or decisive factor of judgment. May be old generations have this creativity of god but the mechanical solidarity in society as described by Emile Durkheim in Division of labour in Society (1893) become a social control machine. Its tool of homogeneity maintained cohesion and integration among individuals which kept ego, feel associated through parallel customs, educational and religious training, work, interdependency and lifestyle. Against it the organic society took a led and gave a message of individualism and provided a freedom of expression.

This judgement is taken positively by the intellectual groups and been considered as a road for moving wheel of social change. In India, social change is always seen with two different ideo- political lens. One ideology, of so called Leftists and other of Rightists. Authors evaluate change or non-change in India from their own moral or ideological view- points (Singh Y. , 1986). The same tendency is manifest when change is treated by some social scientists as equivalent to 'development' and 'progress' (Singh Y. , 1986). But without proper survey and quantification of impact I will make on population, when such change leading laws are framed they attract social boycott.

"Suppose that a new piece of legislation comes into existence, created in the proper formal manner by an accepted law-making institution. What happens? Immediately lawyers set to work, digesting and comprehending the changes brought about by the new rule. The new law is probably published in some official form and finds its way into libraries of law schools, lawyers and administrators. .......the changes are registered in digests of legislation, legal encyclopedias, lawyers' updates or periodicals. But what then? Does anything else happen? Does the law somehow reach the world beyond this rarefied professional sphere? If so, in what way? With what effect?"(Cotterrell, 2007). 
Not every such law will even reach the courts of law because no case may arise to raise the issues with which new law is concerned. Perhaps the matter which is the object of law is not important in the experience of social life or, if it is, for various reasons the issues are kept away from courts. No one sees fit to raise them. Suppose, however, that the new law is invoked before a judge. Even so the court may refuse to apply it. It may be ruled irrelevant or interpreted in such way as to remove some or all of its potential effect.(Cotterrell, 2007). It could be due to the kind of socialization he received or the biasness of the judge towards the ideology due to his knowledge development and wisdom he has as per the common sense index.

But suppose the court does apply the new law to the case under consideration. What effect will the judgement have on the conduct of life outside the courtroom? Very often, surprisingly little may be known by judges and lawyers about the law's potential or actual social effects. Perhaps even more surprisingly, rarely is any systematic attempt made by them to find out(Cotterrell, 2007).

\section{METHODOLOGY}

This study in the field of gender, law and society on sociocultural aspect of judgement of Supreme Court of India on section 377 focus to understand its significance. The sample size of the present study consisted of 150 respondents. Snowball- sampling technique was used to identify respondents. The data was collected through "interview schedule" coupled with observation technique and secondary data.

Profile of the Respondents: It is to be noted that the respondents were university students of under- graduate, post- graduate and Ph.D courses of higher education (100\%) from the city of Gujarat - Vadodara. These respondents were from different states of India where around $30 \%$ from Manipur, 20\% from Gujarat, $20 \%$ Maharashtra, 10\% from Madhya Pradesh, 6\% from Assam, 6\% from Tamil Nadu, $4 \%$ from Kerala $4 \%$ from Bihar. (89\%) of respondents are registered residents of hostel but most of them are living in apartments. Around 66\% respondentsin the study were found to be Hindus belonging to general, scheduled caste, scheduled tribes, and other backward caste categories. 20\% were Christian, $10 \%$ were Muslim and $4 \%$ were Jains by religion. All the $100 \%$ were found in their young and working age group of 20-40 years where around $20 \%$ of students were not able to clear their regular exams and have started jobs but are still registered students of universities in various certificate, diploma and degree courses.

\section{OBJECTIVES OF THE STUDY}

1. To study the judgement on section 377

2. To analyze the judgement with socio- legal, sociocultural\& gender perspectives,

3. To analyze the judgement with Sociology of Prediction
4. To examine the significance of judgement.

\section{RESULTS AND DISCUSSION}

\section{A. Transgender, Law \& Taboo}

The Indian Penal Code 377, Unnatural offences - Whoever voluntarily has carnal intercourse against the order of nature with any man, woman or animal, shall be punished with imprisonment of either discretion for a term which may extend to ten years, and shall also be liable to fine(Act 45 of 1860 - The Indian Penal Code).

But from $6^{\text {th }}$ September 2018, consensual sex between adult humans in private is no longer a crime in India. Decision taken by a five- judge Constitution Bench, comprising Honorable Chief Justice of India Dipak Mishra, Justice RF Nariman, Justice AM Khanwilkar, Justice DY Chandrachud and Justice Indu Malhotra, decriminalized a part of Section 377 of the Indian Penal Code. It's been looked as supremacy of "constitutional morality" over "societal morality". With this 158year old British-era law was scrapped.

Instruments of social control fall in conflict when law challenges the folkways and mores. Social taboo and social sanctions takes the charge to provoke and create an inflammable environment. They are responsible for social control and social order in society. But in complaintof counterculture shield of Habitus as expressed by Pierre Bourdieu. Ideologies will get weighted and allied with appeasement policy.

\section{B. Identity}

NALSA case that is National Legal Services Authority V. Union of India and Others, Justice Radhakrishnan said:-"Gender identity refers to each person's deeply felt internal and individual experience of gender, which may or may not correspond with the sex assigned at birth, including the personal sense of the body which may involve a freely chosen, modification of bodily appearance or functions by medical, surgical or other means and other expressions of gender, including dress, speech and mannerisms. Gender identity, therefore, refers to an individual's selfidentification as a man, woman, transgender or other identified category".

But as per oxford dictionary and sociological understanding, gender is the state of being male or female as expressed by social or cultural distinctions and differences, rather than biological ones.

Due to these differences in opinion this subject requires higher sociological lenses for handing the future predicted social issues raising after the judgement of Supreme Court of India on $6^{\text {th }}$ sept. 2018. Sociology of prediction helps us to understand the conspicuous chain reactions. 
Research conducted in few universities and their environs in Gujarat with 'sociology of prediction' approach, predicts the impact of oriented identity and intentional identity. It was observed that residents get the room allocation by the hostel authorities. Most get settled but few requests for room change. These are the resident- students who complain that the boy staying in that room is gay. Issue expands its intensity when room is three seater that is it can accommodate three person and two are gay. It is been observed that gay has not disclosed his identity and has taken admission as boy, which he is by his sex, biological. But the other resident- students find it difficult to stay with them due to their social behavior. Also, it remains a hidden fact of their identity as who is male gay and who is female gay (men having bio- satisfaction needs as of women). There are also chances that if a boy is sharing room with two gays than immediate social influence may ignite the orientation of sex in his mind and he joins them as third partner. This leads to discover the fact that currently majority of hostels in India are stratified on basis of sex and not on the basis of gender. Gays (gender) in boys (sex) hostel can have intercourse in their rooms illegally (now considered natural) backed by 'constitutional morality' over 'social morality' and same is the case for lesbians. But to have girl and boy in same hostel room 'social morality' takes a lead. Why?

Are the identities going to be reviled or the Iyaari (changing the identity by own wish) will win over 'identity morals' as per the available benefits or economy associated with begging profession. This could be observed from Bollywood industry where many times identity is framed because of social orientation rather than biological or natural condition. Decision is welcomed but arguments required to be analyzed for creating successful social policies and better implementation of awareness programs holding human values.

\section{Sociology of Prediction}

Sociology of Prediction explains the human behavior and concept of presumptions and also explains the pattern of interpretation study of humans is more intricate than study of non-humans. To understand the social action and social facts we need to perform study in the constant social phenomenon to bring steady results. When we keep humans as object and try scientific study, it will produce general results rather than pragmatic. Reason is the dynamic character of society. Bringing constant \& empirical result is to create "Human Robot" where we need controlled environment for experiment. That is, its complete social past should be known than present will be programmed and future actions will be controlled until it encounters new reaction (socialization) till then behavior will be as expected. Sometime "suicide bombers" are holding the behavioral characteristics of "Human Robots". Sociology is a science which is above pure sciences and social sciences. In broader term we can define sociology as "study of reasons and solutions of human action" or "study of evolution, distribution (structure) and function of society" or "study of behavioral reactions"(Singh V. , 2018). It is a scientific approach which is developed to design the most suitable public policy for desired outcomes. This approach being scientific, focuses on qualitative and quantitative analysis of social issues and social change. It uses the concept of common sense in understanding the present trend of society and predicts the future outcome for social behavior. Marvin E. Wolfgang too believed that prediction is a scientific approach and suggested to use it in study of criminology and penology subjects. Sociology of prediction works on implication assessment and could provide us the tentative knowledge about how the society is going to react as per the social change theories and past experiences.

According to Marvin E. Wolfgang, penology and correction are fit subjects for criminology only if scientific methods involving studies, predictions and experiments are employed in these areas.(Siddique, 2009) . Wolfgang continued his support to Science of prediction: "The juvenile court judge who would make use of the 'Social Prediction Scale' devised by the Gluecks and suggested by them as an appropriate guide in sentencing, is not engaging in a scientific pursuit. What the Gluecks have done is criminology; what the judge does with the results of criminology is public administration."(wolfgang, 1963)

Similarly, Max Weber has also kept high reliance on concept of prediction in his understanding of law as a framework for Social Action.

"It is clear that, in Weber's view, law has a central importance both for the economic foundations of capitalism- that is, in facilitating the forms of social action on which capitalism depends- and in fostering and expressing the more general processes of rationalization of life in capital society. Law is accepted in modern Western society not because it expresses dearly held values, not because of the overriding sanctioning power of the state, nor through tradition, nor the charisma of political leaders. It is accepted simply, because it provides a common sensical and comprehensive framework of predictable rules which make it possible for individuals to pursue purpose- rational social action ....... law can often hamper economic activity through the imposition of rigid rules and fixed bureaucratic procedures. But it basically provides the predictable guarantees of enforcement or support of economic transactions that make rational ...."(Cotterrell, 2007)

After understanding the scientific approach of 'Sociology of Prediction' it could be best used for calculating the impacts of Supreme Court judgements which have greater social bearing and direct encounter of long whispered custom. Especially, when these customs have strong attachment with religious beliefs like Shabarimala case (WRIT PETITION (CIVIL) NO. 373 OF 2006). After this judgement, State of Kerala faced lot of violence and public rage against judiciary could be registered. Many people died and situation took a violent turn, where some got benefited 
politically. But for sure this was defeat of judiciary. Goal of judiciary should be the harmony of society as a whole but sometimes it get reversed and questions on the role of judiciary that is constitutional morality verses constitutional law and governance.

Similarly, the judgment of Supreme Court of India on Navtej Singh Johar \& Ors. ...Petitioner(s) Versus Union of India Thr. Secretary Ministry of Law and Justice (Section 377) could invite more dangerous results in social and health sphere.

Long fight for the rights of LGBTQ community is going in America. But still nothing as great as India did has happened in America. It creates a pressure zone for current government and upraises the Indian government's ideology and grace the nation at global level. This attracts the diaspora vote bank in support of running government in India. At the same phase, this may create more huddles for current government in America. If such environmental changes could be noticed than as per "Sociology of Prediction" it will be first time when India becomes the game changer in International diplomacy. This diplomatic move sounds impressive but may cost heavy as still big questions on the health security of nation and on male rape victims is not taken into consideration. What is the interrelation between decriminalizing 377 and HIV? Also, this is start of the new phase as earlier laws were framed as per social norms which are now better reframed as "Law is the mirror of society". So, if you wish to understand Indian social system and social change encountered \& accepted than just go through the latest judgements of Honorable Supreme Court. Also, this will assists the social scientists to think about the upcoming social change and impact of Giddens juggernaut of modernity (Ritzer, 2010) with the help of "Sociology of Prediction" approach and prediction perspective.

It is time to reflect on past particularly during the freedom movement and the constitutional journey that India had for the last 70 year. To be able to understand those murrains that the destiny is awaiting for India as one of the world leaders in the $21^{\text {st }}$ century. It is going to be the fact that twenty first century is going to be the era of Asia and particularly India because of the face changing judgments of Supreme Court. These judgements are nothing less than attack of culture but the fact is hidden in its defensive and developmental strategy. We could consider that Supreme Court of India is playing the role of parents who are providing anticipatory socialization to the citizens. Because if India has to stand strong in front of juggernaut of modernity than its time for acceptance of social changes. Resistance to such judgements are the result of cultural $\operatorname{lag}($ Ogburn, 1922). It is rightly said that "everything is right somewhere sometime, not everywhere every time", and this is the time or era of reasoning and change.

And if India have to follow that destiny, Indians have to remember their culture of more than 2500 years, which kept
India a distinct civilization. That has contributed to the world at large. This time again India is taking lead by accepting the demands of Social change and setting examples for other nations. We should not forget that history in the era of technological development and globalization, where the develop countries will have a greater say in organization of things. We are aware about many social reformers but this time Supreme Court of India has played very impressive role in leading the social movements.

\section{FINDINGS AND SUGGESTIONS}

Researcher found that the judgment was supported by majority of literates in society. So, there is no space left to discuss on the matter or question "Is the judgement of Supreme court of India on section 377 right or wrong?" Definitely this is a right and appreciable judgement.

Only concern found was that the judgment didn't took health sector in consideration with the decision been made. Also an important issue of male rape victim remained untouched. There is no law for male rape victims. Earlier section 377 was a kind of protection when a man gets raped by a male man. But now after decriminalizing this section there is a chance of increasing number of male rape cases as per the sociology of prediction. Law can't work effectively until and unless empirical legal methods are not taken into consideration when the judgment is associated by bigger population and culture. Normative legal methods are effective till the time they are focusing the crime related issues and individual criminals or small group of criminals are taken into consideration. Here, the judgement is relative to major population and is need of the minority. For long, this kind of behavior is considered unacceptable by the society and law. And there was no awareness diffused in society before the judgement was taken. That is the reason its effectiveness is less on acceptance scale but could harm more. Police and sections of law \& order need to work a lot.

\section{CONCLUSION}

After a carefully conducted scientific study it could be concluded that the judicial institutions need to understand the impact of the judgements registered. It has to accept that sources of law are folkways and mores, which are focused on maintenance of morals, values and ethics in society. Before the judgements are taken, multidisciplinary study of the issue should be conducted and it must be verified with sociology of prediction. This could provide us tentative implication assessment and could give us the picture of its significance and impact. It is also noteworthy that with the increasing impact of industrialization and urbanization we are encountering the changing face of human values.

It could be considered that major social institutions are bump into reverse model. What all social norms were set for smooth processing of social order are slowly deleting. Individualization is the major factor behind all these 
changes and it is supported by capitalization. What was there is past got changed in present and what is there in present is in process of change for future. So, we can conclude that everything is right somewhere sometime but not everywhere every time. Judgement of Supreme Court of India on section 377 is appreciable but increase in healthcare issues (HIV) and male rape victim issue will be offspring's of this judgement if timely actions are not taken on these ignored issues.

\section{REFERENCES}

[1] Ahuja, R. (1993). Indian Social System. Jaipur: Rawat Publication.

[2] Atal, Y. (2008). Changing Indian Society. Delhi: Rawat Publication.

[3] Baxi, U. (1982). The Crisis of Indian Legal System. New Delhi: Vikas Publishing House.

[4] Baxi, U. (1986). Towards a Sociology of Indian Law. New Delhi: Satvahan Publications.

[5] Bhat, I. P. (2012). Law \& Social Transformation. New Delhi: Eastern Book Company.

[6] Cotterrell, R. (2007). The Sociology of Law: An Introduction. New Delhi: Oxford University Press.
[7] Chundawat, V.S. (2015). Sociology of Science and Prediction, International Journal of Development Research, 10(5), 5888-5890.

[8] Inkels, A. (1977). What is Sociology: A guide to problems and Literature. Bombay: Blackie\& Son.

[9] Marc, G. (1989). Law and Society in Modern India. New Delhi: Oxford University Press.

[10] Marcus, G. (2016). Do the companionship and community networks of older LGBT adults compensate for weaker kinship networks? Quality in Ageing and Older Adults, 17(1), 36-49.

[11] https://doi.org/10.1108/QAOA-07-2015-0032

[12] Peter, T. (2011). Taking advantage: informal social mechanisms and equal opportunities policies. International Journal of Sociology and Social Policy, 31(5/6), 253-271.

[13] Singh, Y. (1986). Modernization of Indian Tradition. New Delhi: Rawat Publication.

[14] Singh, Y. (1986). Social Stratification and Change in India. New Delhi: Manohar Publication.

[15] Shah, G. (1990). Social Movements in India: A Review of Literature. New Delhi: Sage Publication.

[16] Turner, J. H. (1994). Sociology: Concepts and Uses. New York: McGraw Hill.

[17] Uberoi, P. (1994). Family, Kinship and Marriage in India. New Delhi: Oxford University Press.

[18] Vago, S. (1981). Law and Society. New Jersey: Prentice Hall. 